\title{
Investigating Febrile Polyserositis: An Unusual Case of Idiopathic Hypereosinophilic Syndrome
}

\author{
$\underline{\text { Inês Rueff Rato }}{ }^{1}$, Joana Rigor ${ }^{1}$, Paula Ferreira ${ }^{1}$, Joana Laranjinha², Gualter Santos-Silva ${ }^{3}$, Daniela Martins-Mendes ${ }^{1,4,5}$ \\ ${ }^{1}$ Internal Medicine Department, Centro Hospitalar de Vila Nova de Gaia/Espinho, Porto, Portugal \\ ${ }^{2}$ Infectious Diseases, Hospital Pedro Hispano, Porto, Portugal \\ ${ }^{3}$ Cardiology Department, Centro Hospitalar de Vila Nova de Gaia/Espinho, Porto, Portugal \\ ${ }^{4}$ Biomedicine Department, Faculty of Medicine of Porto University, Porto, Portugal \\ ${ }^{5}$ i3S - Institute for Research and Innovation of Porto University, Porto, Portugal
}

\section{Doi: 10.12890/2021_002426- European Journal of Case Reports in Internal Medicine - ๑ EFIM 2021}

Received: 26/02/2021

Accepted: 15/03/2021

Published: 02/04/2021

How to cite this article: Rueff Rato I, Rigor J, Ferreira P, Laranjinha J, Santos-Silva G, Martins-Mendes D. Investigating febrile polyserositis: an unusal case of idiopathic hypereosinophilic syndrome. EJCRIM 2021;8: doi:10.12890/2021_002426.

Conflicts of Interests: The Authors declare that there are no competing interests.

Acknowledgements: The authors would like to thank Unilabs and Dr Susana Guimarães for providing the pathology images.

This article is licensed under a Commons Attribution Non-Commercial 4.0 License

\begin{abstract}
Hypereosinophilic syndrome (HES) is a heterogenous group of diseases characterized by abnormal accumulation of eosinophils in the blood or peripheral tissues. It can affect all organs and therefore clinical manifestations are highly variable. We describe the case of a 38-yearold man admitted for febrile polyserositis. He developed cardiac tamponade requiring pericardiocentesis complicated by left ventricle perforation which was successfully repaired. He presented mild peripheral eosinophilia. Bronchoalveolar lavage evidenced eosinophilic alveolitis, and pleural and pericardium histopathology revealed the presence of abundant eosinophils. All other causes of tissue eosinophilia were excluded and the diagnosis of idiopathic HES was made. The patient was started on glucocorticoids with resolution of symptoms. This case report describes a rare but potentially fatal presentation of HES and demonstrates the difficulty and delay in diagnosis when peripheral hypereosinophilia is absent.
\end{abstract}

\section{LEARNING POINTS}

- Hypereosinophilic syndrome (HES) is characterized by abnormal accumulation of eosinophils in the blood or peripheral tissues.

- The clinical manifestations of HES are highly variable.

- It may be difficult to diagnose HES when peripheral hypereosinophilia is absent.

\section{KEYWORDS}

Hypereosinophilic syndrome, polyserositis, eosinophilic alveolitis, eosinophilic pleurisy, eosinophilic pericarditis

\section{INTRODUCTION}

Hypereosinophilic syndrome (HES) is a heterogenous group of rare diseases characterized by abnormal accumulation of eosinophils in the blood or peripheral tissues ${ }^{[1]}$. Any system can be affected, but the most common are the cutaneous, cardiovascular, pulmonary and haematological systems ${ }^{[2]}$. Tissue damage is more likely to occur when the absolute eosinophil count (AEC) exceeds $1500 / \mu l$, but peripheral blood eosinophilia does not accurately predict the risk of organ damage. Clinical manifestations are highly variable, ranging from asymptomatic eosinophilia to end-organ failure, developing insidiously or acutely with rapid progression ${ }^{[2,3]}$. Glucocorticoids are used as a 
first-line agent followed by the introduction of a steroid-sparing agent if needed ${ }^{[3]}$. Imatinib mesylate and other immunomodulatory agents have shown promising results ${ }^{[2]}$.

\section{CASE DESCRIPTION}

A 38-year-old male chef was admitted to the emergency department with dyspnoea on moderate exertion and a 1-month history of pleuritic chest pain with progressive worsening. He had experienced evening fever since the previous week, dry cough, asthenia, and an episode of paroxysmal nocturnal dyspnoea the night before admission. He had no previous diseases and was not taking regular medication, but did have contact with a patient being treated for active pulmonary tuberculosis 3 years previously. On physical examination, he was febrile, tachycardic, tachypnoeic and had respiratory insufficiency requiring supplemental oxygen. Pulmonary auscultation demonstrated absent breath sounds in both lung bases. The remaining physical examination was unremarkable, including the skin and testis. Laboratory findings revealed eosinophil count 230/pl (<700), C-reactive protein $17 \mathrm{mg} / \mathrm{dl}(<0.5)$, sedimentation rate $85 \mathrm{~mm} / \mathrm{hr}(<15)$ and N-terminal proB-type natriuretic peptide $55 \mathrm{pg} / \mathrm{ml}(<125)$. There was bilateral pleural effusion on chest radiography (Fig. 1A) and computed tomography (CT) angiography of the thorax showed pleural and pericardial effusion. There was vestigial intraperitoneal free fluid on abdominal ultrasound. The electrocardiogram was unremarkable. The patient was hospitalized for febrile polyserositis. The transthoracic echocardiogram revealed moderate pericardial effusion with signs of haemodynamic compromise (Fig. 1B) resulting in cardiac tamponade. The patient required pericardiocentesis which was complicated by left ventricle perforation, followed by cardiac arrest and successful emergent surgical correction.

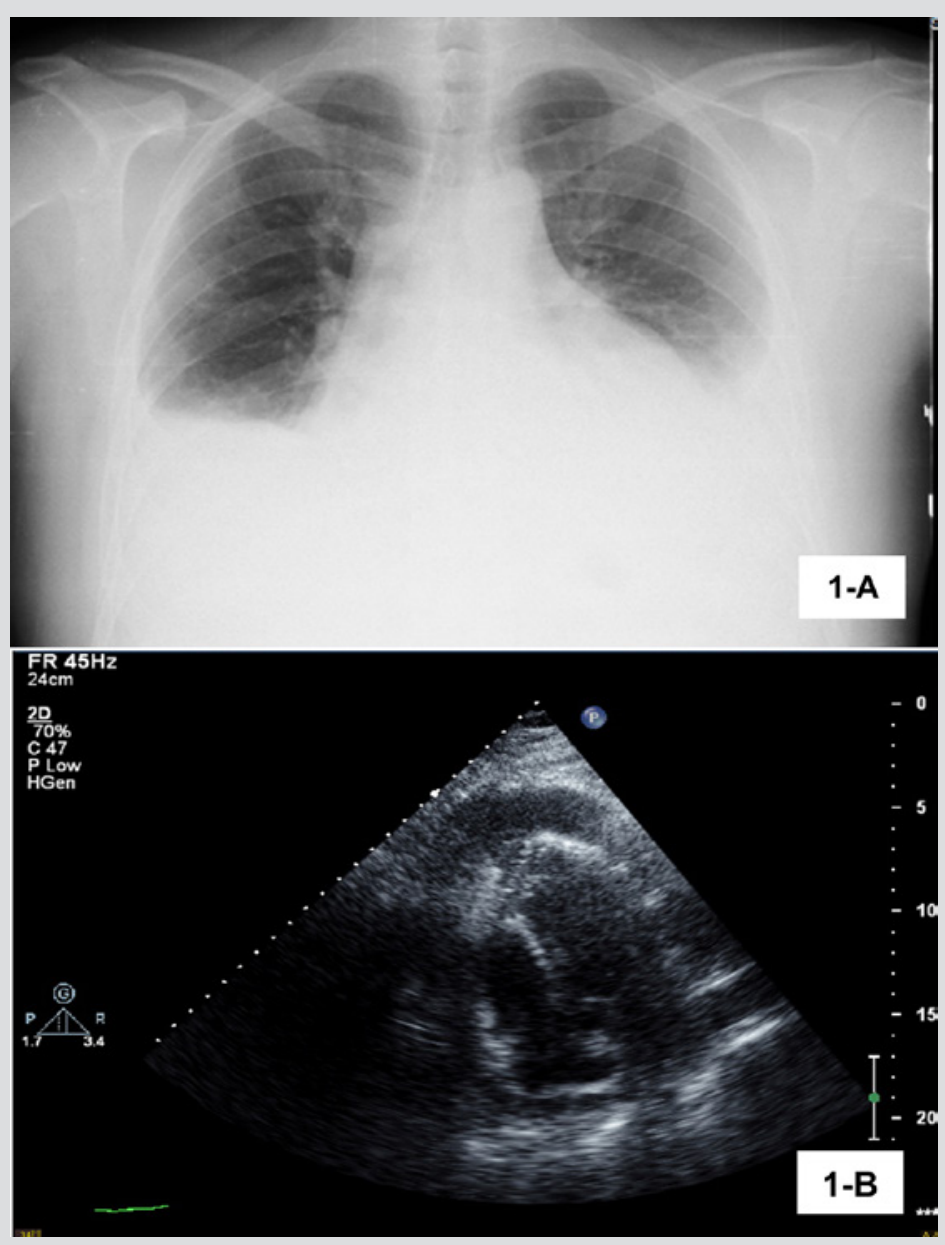

Figure 1 (A) Chest $x$-ray on admission showing bilateral pleural effusion. (B)

Transthoracic echocardiogram showing moderate pericardial effusion with signs of haemodynamic compromise

After a period of recovery in the surgical ward, the patient was readmitted to internal medicine care for further study. We were able to exclude infectious, autoimmune, endocrine and haematological aetiologies (Table 1). The patient tested positive on an interferon-gamma release assay (IGRA). CT scanning of the thorax, abdomen and pelvis as well as a positron emission tomography scan revealed no additional findings. 
Pleural fluid examination showed characteristics of exudate with mononuclear predominance (1043/ $\mu$ l leucocytes with $55.7 \%$ mononuclear cells). Bronchoalveolar lavage evidenced eosinophilic alveolitis (6.2\% eosinophils) with negative cultures. Histopathological examination of pleura was consistent with subacute pleurisy with eosinophils (Fig. 2), and pericardium histopathology revealed subacute fibrinous pericarditis with abundant eosinophils (Fig. 3). The peak of AEC in peripheral blood was 830 cells/ $\mu$ l (Fig. 4). We did not find any genetic rearrangements of the PDGFRA or PDGFRB genes on peripheral blood. Based on these findings, the diagnosis of idiopathic HES was made and the patient was started on $1 \mathrm{mg} / \mathrm{kg} / \mathrm{day}$ of prednisolone. Tuberculosis prophylaxis with isoniazid was also instituted. He showed clinical improvement within the next few days and was discharged home. The dose of corticosteroid was gradually tapered and discontinued after 6 months. Five years later, the patient remains on regular follow-up with no evidence of disease recurrence.

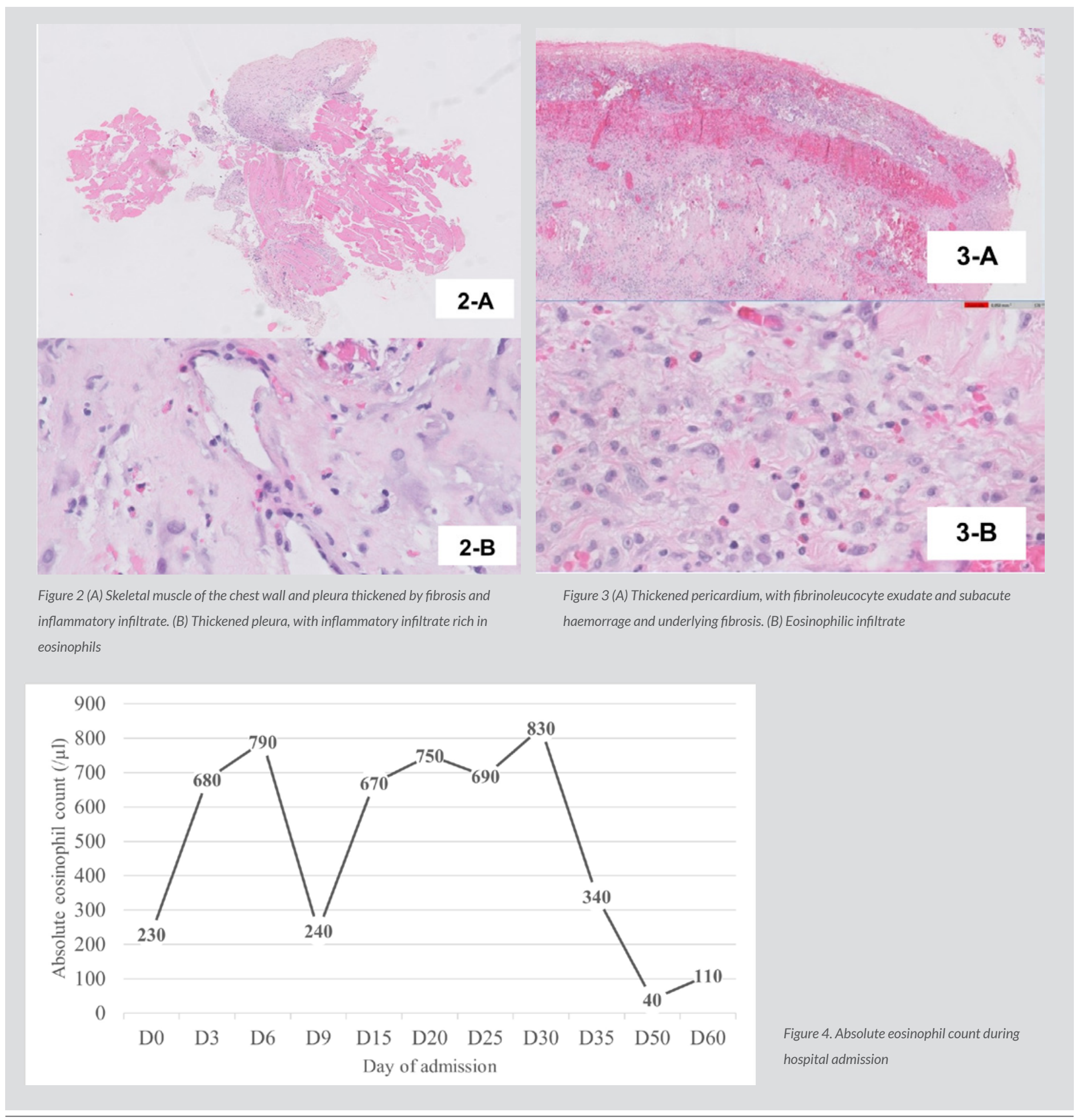




\begin{tabular}{|c|c|c|}
\hline & Patient & Reference \\
\hline \multicolumn{3}{|l|}{ General } \\
\hline Haemoglobin (g/dl) & 12.8 & $13.0-18.0$ \\
\hline Leucocyte count $\left(10^{3} / \mu l\right)$ & 11.22 & $3.8-10.6$ \\
\hline Neutrophils & 7.68 & $1.3-8.8$ \\
\hline Eosinophils & 0.83 & $<0.7$ \\
\hline Platelet count $(103 / \mu l)$ & 336 & $150-440$ \\
\hline Creatinine (mg/dl) & 0.76 & $0.67-1.17$ \\
\hline $\mathrm{LDH}(\mathrm{U} / \mathrm{I})$ & 146 & $135-225$ \\
\hline C-reactive protein (mg/dl) & 17 & $<0.5$ \\
\hline Sedimentation rate $(\mathrm{mm} / \mathrm{hr})$ & 85 & $<15$ \\
\hline Troponin T (ng/l) & 11 & $5-14$ \\
\hline NT-proBNP (pg/ml) & 55 & $<125$ \\
\hline $\mathrm{TSH}(\mu \mathrm{IU} / \mathrm{ml})$ & 2.30 & $0.27-4.2$ \\
\hline Vitamin B12 (pg/ml) & 474 & $197-771$ \\
\hline Folate (ng/ml) & 12 & $4.6-18.7$ \\
\hline \multicolumn{3}{|l|}{ Infection } \\
\hline $\begin{array}{l}\text { Blood (x4), pleural fluid and bronchoalveolar lavage } \\
\text { microbiology }\end{array}$ & \multicolumn{2}{|l|}{ Negative } \\
\hline $\begin{array}{l}\text { Mycoplasma pneumoniae, Chlamydia pneumoniae, } \\
\text { Legionella pneumophila, Rickettsia conorii, } \\
\text { Brucella, Borrelia, Treponema pallidum }\end{array}$ & \multicolumn{2}{|l|}{ Negative } \\
\hline Hepatitis A, B, C, HIV & \multicolumn{2}{|l|}{ Negative } \\
\hline $\begin{array}{l}\text { Sputum, pleural fluid and bronchoalveolar lavage } \\
\text { for Mycobacterium tuberculosis }\end{array}$ & \multicolumn{2}{|l|}{ Negative } \\
\hline Interferon-gamma release assay & \multicolumn{2}{|l|}{ Positive } \\
\hline $\begin{array}{l}\text { Cytomegalovirus, parvovirus, Epstein-Barr virus, } \\
\text { herpes simplex and varicella zoster virus }\end{array}$ & \multicolumn{2}{|l|}{ Negative } \\
\hline Echinococcus granulosus & \multicolumn{2}{|l|}{ Negative } \\
\hline Stool for Giardia lamblia, Cryptosporidium & \multicolumn{2}{|l|}{ Negative } \\
\hline \multicolumn{3}{|l|}{ Immunology } \\
\hline Immunoglobulins G, M, A, E & \multicolumn{2}{|c|}{ Within the reference range } \\
\hline Serum protein electrophoresis, C3, C4 & \multicolumn{2}{|c|}{ Within the reference range } \\
\hline $\begin{array}{l}\text { Antinuclear antibodies, anti-double-stranded } \\
\text { DNA, rheumatoid factor, antineutrophil cytoplasmic } \\
\text { antibodies }\end{array}$ & \multicolumn{2}{|c|}{ Within the reference range } \\
\hline \multicolumn{3}{|l|}{ Haematology and Oncology } \\
\hline PDGFRA gene mutations & \multicolumn{2}{|l|}{ Negative } \\
\hline Karyotype & \multicolumn{2}{|c|}{$46, X Y[20]$} \\
\hline Bone marrow aspiration and biopsy & \multicolumn{2}{|c|}{ No alterations found } \\
\hline Human chorionic gonadotropin (mIU/ml) & $<2.0$ & $0-2$ \\
\hline
\end{tabular}

Table 1. Laboratory findings

Values in red are out of range 


\section{DISCUSSION}

Cardiac involvement in HES is common ${ }^{[4]}$, but pericardial involvement is estimated to be less than $10 \%{ }^{[5]}$. There are several case reports on HES presenting as cardiac tamponade ${ }^{[4-9]}$, but to our knowledge this is the first case without peripheral hypereosinophilia. Our patient presented with only mild peripheral eosinophilia which led to a delay in diagnosis. Only when histopathology reports showed tissue damage due to presence of eosinophils did the diagnosis became apparent. In the setting of HES, patients usually present with peripheral blood hypereosinophilia and eosinophilia-related target organ damage ${ }^{[3]}$. However, it is worth mentioning that the diagnostic criteria include tissue infiltration that is extensive in the subjective opinion of a pathologist ${ }^{[1]}$. The diagnosis of idiopathic HES was established as all other known causes of eosinophil dysfunction were excluded. The aim of therapy in HES is to reduce the eosinophilic granulocyte count in tissues, and glucocorticoids are generally recommended as first-line therapy ${ }^{[4,7]}$. Our patient responded well to prednisolone with iatrogenic diabetes during treatment that was well controlled with metformin and sitagliptin. However, if prednisolone is not suitable, many other regimens are available, including steroid-sparing agents, a tyrosine-kinase inhibitor (imatinib) or immunomodulatory agents ${ }^{[2,3]}$. Because of profound immunosuppression during treatment, it is important that infectious diseases are excluded. Our patient had previous contact with a patient being treated for active pulmonary tuberculosis a few years earlier and tested positive for IGRA. Therefore, it was mandatory to exclude active infection and start treatment for latent tuberculosis.

\section{CONCLUSION}

The authors consider that this case is unique because of the severity of organ dysfunction (eosinophilic alveolitis, pleurisy and pericarditis) in the absence of hypereosinophilia. Clinical expertise and attention are needed in the diagnosis of rare diseases, especially with atypical presentations, to ensure the best outcomes.

\section{REFERENCES}

1. Valent P, Klion AD, Horny HP, Roufosse F, Gotlib J, Weller PF, et al. Contemporary consensus proposal on criteria and classification of eosinophilic disorders and related syndromes. J Allergy Clin Immunol 2012;130(3):607-612.e9.

2. Curtis C, Ogbogu P. Hypereosinophilic syndrome. Clin Rev Allergy Immunol 2015;50(2):240-251.

3. Hsieh F. Hypereosinophilic syndrome. Ann Allergy Asthma Immunol 2014;112(6):484-488.

4. Moza A, Sheikh M, Rock-Willoughby J, Cooper C, Kanjwal Y. Idiopathic hypereosinophilic syndrome presenting with cardiac tamponade. Heart Lung 2012;41(6):e15-e17.

5. Fernandez A, Ahmed S, Duncan B, Firshein S, Kluger J. Cardiac tamponade: a rare complication of idiopathic hypereosinophilic syndrome. J Cardiovasc Med 2009;10(2):188191.

6. Beynel P, Nesme P, Perol M, Guerin JC. [Association of idiopathic eosinophilic pleurisy and a severe pericardial effusion]. Rev Mal Respir 1997;14(3):218-220.

7. Wu P, Chen Y, Zhang H, Li C. Idiopathic hypereosinophilic syndrome presenting with multiple organ damage. Medicine 2019;98(10):e14532.

8. Kazama R, Okura Y, Hoyano M, Toba K, Ochiai Y, Ishihara N, et al. Therapeutic role of pericardiocentesis for acute necrotizing eosinophilic myocarditis with cardiac tamponade. Mayo Clin Proc 2003;78(7):901-907.

9. Kiani R, Naghavi B, Amin A, Sadeghpour A, Zahedmehr A, Firouzi A, et al. Central nervous system and cardiac involvement in the hypereosinophilic syndrome: a case report. Immunol. Invest 2020; 1-7. doi: 10.1080/08820139.2020.1758131. Online ahead of print. 